\title{
Volker Weber
}

\section{Thomas Schwentick • Herik Björklund}

The special issue is dedicated to the memory of Volker Weber whose untimely death occurred on April 7th 2009. Thomas Schwentick, Volker's PhD supervisor and Herik Björklund have written the following obituary:

We mourn the loss of Volker Weber, who died suddenly and unexpectedly on the 7th of April 2009. He was 30 years old. Volker began his scientific work at the faculty of Mathematics and Computer Science of the Philipps-Universität in Marburg. The main results of his masters thesis were published in a leading theoretical Computer Science conference.

Since October 2005, Volker worked as a researcher and PhD student at the Technische Universität Dortmund. His dissertation dealt with the complexity and expressiveness of hybrid logics, and was at the time of his death close to completion. Volker had fast become one of the leading experts in the field of hybrid logics.

Furthermore, Volker was actively involved in the self-administration of the faculty. In particular, he always had an open ear for the opinions of students and worked hard in various committees to improve the teaching offered by the faculty. Not least, Volker was a talented and committed teacher of Computer Science. Volker's colleagues at the University will miss him deeply, as a friend and as a co-worker.

T. Schwentick ( $\varangle)$

TU Dortmund Fakultät für Informatik, Otto-Hahn-Str. 16, Raum 214, 44227 Dortmund, Germany

e-mail: thomas.schwentick@udo.edu

H. Björklund

Umeå Universitet, 90187, Umeå, Sweden 